\title{
Angioarchitecture Related to Hemorrhage in Cerebral Arteriovenous Malformations
}

\author{
Shinji HiraI, Seiichiro MINE, Iwao YAMAKAMI, Junichi ONO, \\ and Akira YAMAURA
}

Department of Neurosurgery, Chiba University School of Medicine, Chiba

\begin{abstract}
A retrospective study was conducted to determine the angioarchitecture related to hemorrhage in patients with cerebral arteriovenous malformations (AVMs), who underwent conservative treatment and long-term follow-up. The average observation period was 9.3 years, and the annual bleeding rate was estimated at $3.6 \%$. In all cases angiographic findings were reviewed in detail. The average $A V M$ grade by Spetzler-Martin was 3.5. Higher bleeding rate was observed in large AVM (5.4\%) compared with small $(2.1 \%)$ or medium AVM $(2.9 \%)$. Deep venous drainage $(8.6 \%$ year) was strongly correlated to hemorrhage. Concerning location of nidus, hemorrhage was frequently found in insular, callosal, and cerebellar AVMs. Venous ectasia, feeder aneurysm, and external carotid supply were commonly demonstrated on angiograms. Comparison of annual bleeding rate revealed that AVMs with intranidal aneurysm $(8.5 \%)$ and venous stenosis $(5.5 \%)$ had a high propensity to hemorrhage. Therapeutic strategy should be focused on these potentially hazardous lesions by the use of endovascular embolization or stereotactic radiosurgery, even if surgical resection is not indicated.
\end{abstract}

Key words: arteriovenous malformation, hemorrhage, angioarchitecture, natural history

\section{Introduction}

In management of cerebral arteriovenous malformations (AVMs), the most serious complication is hemorrhage due to rupture of AVM. Recently, the relationship between hemorrhage and angioarchitecture has been analyzed precisely. ${ }^{9.11-13,16,20,23)}$ These studies, however, are not based on a long-term follow-up which would tell us what kind of angiographic characteristics actually tends to cause bleeding from the AVM. Information about the actual source of bleeding would also contribute to developing therapeutic strategies. The aim in this study is to clarify potentially dangerous structures which might initiate bleeding, from analysis of clinical observation and radiological findings.

\section{Materials and Methods}

The study was conducted retrospectively in 24 patients with cerebral AVM, who underwent conservative management. In these patients surgical intervention was avoided, because of high therapeutic risk or rejection of treatment by the patients. They were diagnosed with conventional angiograms or digital subtraction angiograms. Some of the patients underwent superselective angiograms with microcatheters. Clinical course was investigated at the outpatient clinic or by correspondence with the patients. The follow-up period in every patient was 1 year or more. In patients who underwent subsequent therapeutic embolization or radiotherapy, the period after the treatment was excluded from this study.

All AVMs were evaluated with Spetzler-Martin grading system, which consists of size, eloquence, and pattern of venous drainage. ${ }^{19)}$ Furthermore, characteristics on angiograms in each AVM were listed as the following types: 1) arteriovenous fistula, 2) external carotid supply, 3) angiomatous change, 4) feeder aneurysm, 5) intranidal aneurysm, 6) venous ectasia, and 7) venous stenosis. ${ }^{9,23)}$ In the patients who experienced hemorrhagic episodes during the follow-up period, location of bleeding was retrospectively examined by computed tomography (CT) or magnetic resonance (MR) imaging, if available. 
Table 1 Location, size, and drainage and hemorrhage during follow-up

\begin{tabular}{|c|c|c|c|c|}
\hline & No. of cases & $\begin{array}{l}\text { Times of } \\
\text { bleeding }\end{array}$ & $\begin{array}{l}\text { Follow-up period } \\
\text { (months) }\end{array}$ & $\begin{array}{c}\text { Bleeding rate } \\
\text { per year }(\%)\end{array}$ \\
\hline \multicolumn{5}{|l|}{ Location* } \\
\hline frontal & 11 & 3 & 1580 & 2.3 \\
\hline parietal & 9 & 5 & 1467 & 4.1 \\
\hline occipital & 3 & 0 & 248 & 0 \\
\hline temporal & 2 & 0 & 191 & 0 \\
\hline insular & 1 & 1 & 97 & 12.4 \\
\hline callosal & 2 & 1 & 164 & 7.3 \\
\hline thalamic & 1 & 0 & 44 & 0 \\
\hline cerebellar & 4 & 1 & 274 & 4.4 \\
\hline \multicolumn{5}{|l|}{ Size } \\
\hline$<3 \mathrm{~cm}$ & 8 & 1 & 561 & 2.1 \\
\hline $3-6 \mathrm{~cm}$ & 9 & 3 & 1245 & 2.9 \\
\hline$>6 \mathrm{~cm}$ & 7 & 4 & 887 & 5.4 \\
\hline \multicolumn{5}{|l|}{ Drainage } \\
\hline superficial & 9 & 2 & 1119 & 2.1 \\
\hline deep & 5 & 2 & 278 & 8.6 \\
\hline mixed & 10 & 4 & 1296 & 3.7 \\
\hline Total & 24 & 8 & 2693 & 3.6 \\
\hline
\end{tabular}

${ }^{*}$ An arteriovenous malformation can be located in two or more regions.

Table 2 Angioarchitecture and hemorrhage during follow-up

\begin{tabular}{lcccc}
\hline \multicolumn{1}{c}{ Type* } & No. of cases & $\begin{array}{c}\text { Cases of } \\
\text { initial bleeding }\end{array}$ & $\begin{array}{c}\text { Times of bleeding } \\
\text { in follow-up }\end{array}$ & $\begin{array}{c}\text { Bleeding rate } \\
\text { per year (\%) }\end{array}$ \\
\hline External carotid supply & 4 & 1 & 3 & 4.4 \\
Angiomatous change & 3 & 0 & 0 & 0 \\
Arteriovenous fistula & 2 & 0 & 0 & 0 \\
Feeder aneurysm & 4 & 2 & 4 & 4.9 \\
Intranidal aneurysm & 2 & 1 & 2 & 8.5 \\
Venous ectasia & 8 & 2 & 1 & 1.1 \\
Venous stenosis & 2 & 1 & 1 & 5.5 \\
No specific findings & 13 & 2 & 2 & 4.1 \\
\hline
\end{tabular}

*An arteriovenous malformation can be classified into two or more types.

\section{Results}

\section{Overview of patients}

The patients comprised 14 males and 10 females. Age at first onset ranged from 1 to 56 years, an average of 30.3 years. The follow-up period ranged from 12 to 508 months, 112 months (9.3 years) on average. Clinical manifestations at the first onset were hemorrhage in six cases $(25 \%)$, epilepsy in five $(21 \%)$, progressive neurological deficits in six $(25 \%)$, and no specific symptoms in seven $(29 \%)$. Two patients $(8.3 \%)$ died of hemorrhage during the follow-up.

\section{AVM structure and hemorrhage}

The average Spetzler-Martin grade in the whole series was 3.5. With $\mathrm{CT}$ scan or MR imaging nine hemorrhagic events during the follow-up period were confirmed in seven cases. The annual bleeding rate in the whole population was estimated to be $3.6 \%$ from incidence of hemorrhage (8 times), divided by total follow-up years (224.4 years) (Table 1). The annual bleeding rate in relation to the location, size, and drainage was also calculated. High incidence of hemorrhage was noted in insular $(12.4 \% / \mathrm{yr})$ and callosal (7.3\%/yr) AVMs. Concerning size of nidus, large AVM relatively tended to bleed (5.4\%/yr). 
An AVM with deep venous drainage frequently bled $(8.6 \% / y r)$.

\section{Angioarchitecture and hemorrhage}

Types of angioarchitecture in the series were listed in Table 2. Venous ectasia, feeder aneurysm, and external carotid supply were commonly observed. The relationship between risk of hemorrhage and angioarchitecture was analyzed. AVMs with intranidal aneurysm $(8.5 \% / y r)$ and venous stenosis $(5.5 \% / y r)$ frequently bled, compared with AVMs with no specific findings $(4.1 \% / \mathrm{yr})$. In contrast, no hemorrhagic events were observed in angiomatous change or arteriovenous fistula.

\section{Illustrative Cases}

Case 1: In June 1985, a 43-year-old female experienced a headache, and was diagnosed as harboring a left frontoparietal AVM. A feeder aneurysm arising from the left middle cerebral artery and a dilated portion within the nidus, or intranidal aneurysm, were clearly seen on the angiogram (Fig. 1). In February 1996, she suffered an attack of hemiparesis and aphasia, and MR images proved a left frontal hematoma situated outside of the nidus (Fig. 2). The bleeding appeared to have been triggered not by the feeder aneurysm, but by the intranidal aneurysm, because it was adjacent to the hematoma. The intranidal aneurysm had disappeared on the second angiogram (Fig. 3). She underwent endovascular embolization twice, followed by stereotactic radiosurgery. No subsequent hemorrhage has been recognized after the treatment.
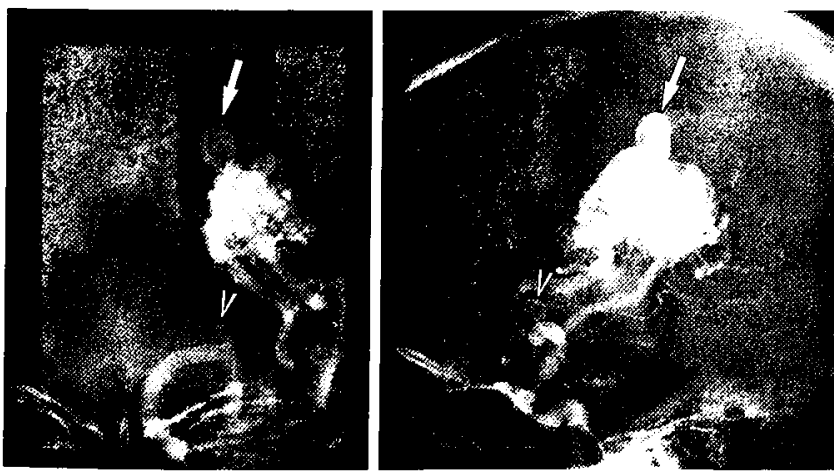

Fig. 1 Case 1. Left internal carotid angiograms, frontal (left) and lateral views (right) before hemorrhagic attack, showing an intranidal aneurysm (arrow) and feeder aneurysm arising from the middle cerebral artery (arrowhead).
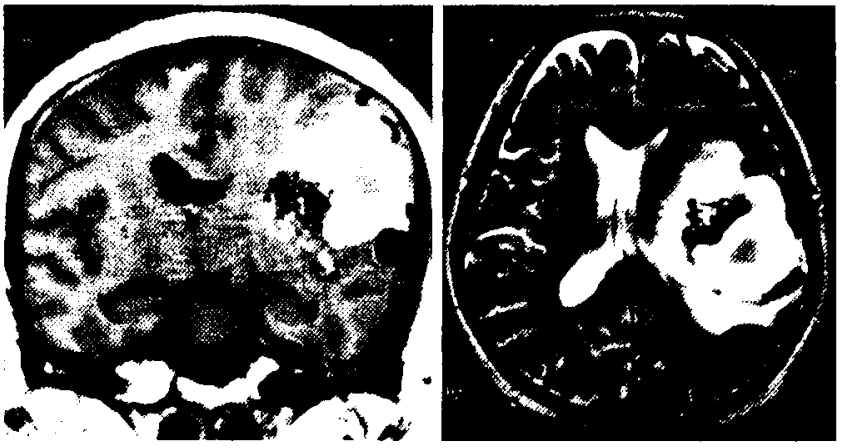

Fig. 2 Case 1. Coronal $\mathrm{T}_{1}$-weighted (left) and axial $\mathbf{T}_{2}$-weighted (right) magnetic resonance images demonstrating a left frontal hematoma located lateral to the nidus.
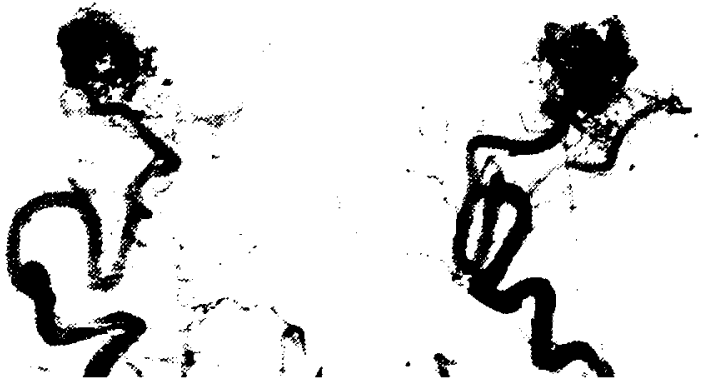

Fig. 3 Case 1. Left internal carotid angiograms, frontal (left) and lateral views (right) after the hemorrhage, showing disappearance of the intranidal aneurysm.

Case 2: A 46-year-old male had undergone a therapy for epilepsy for 8 years. Carotid angiograms revealed a left frontal AVM, associated with an arterial aneurysm arising from the anterior cerebral artery, and with an intranidal aneurysm which did not directly connect to a drainer (Fig. 4). In February 1991, he experienced a mild right hemiparesis due to hemorrhage. CT scan showed a crescent high density area on the posteromedial surface of the partly calcified nidus (Fig. 5), hence the bleeding seemed to be from the intranidal aneurysm, not from the arterial aneurysm. He has preferred a conservative treatment with antiepileptic drugs. 


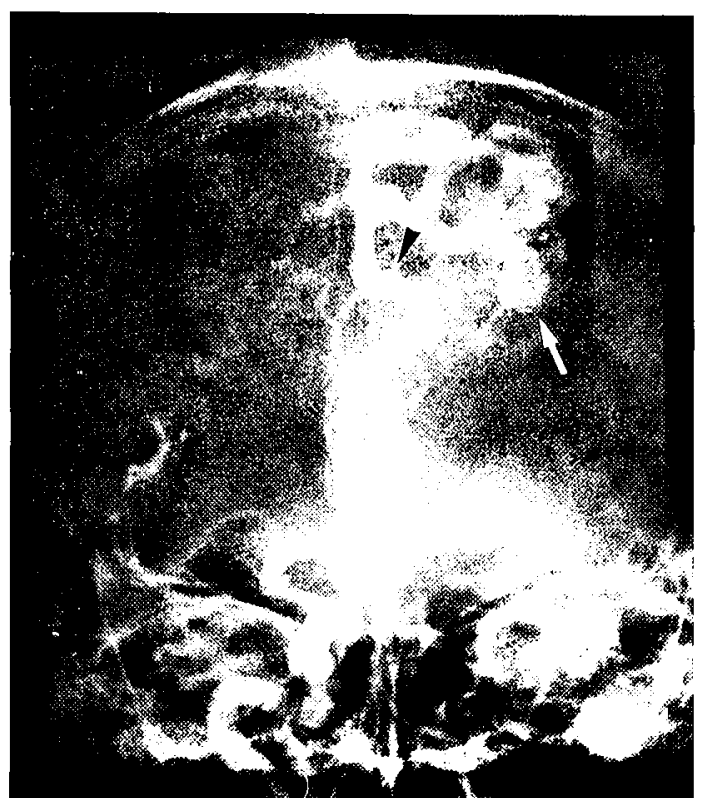

Fig. 4 Case 2. Left internal carotid angiogram, frontal view, showing an intranidal aneurysm located lateral of the nidus (arrow), and a feeder aneurysm arising from the anterior cerebral artery near the midline (arrowhead).

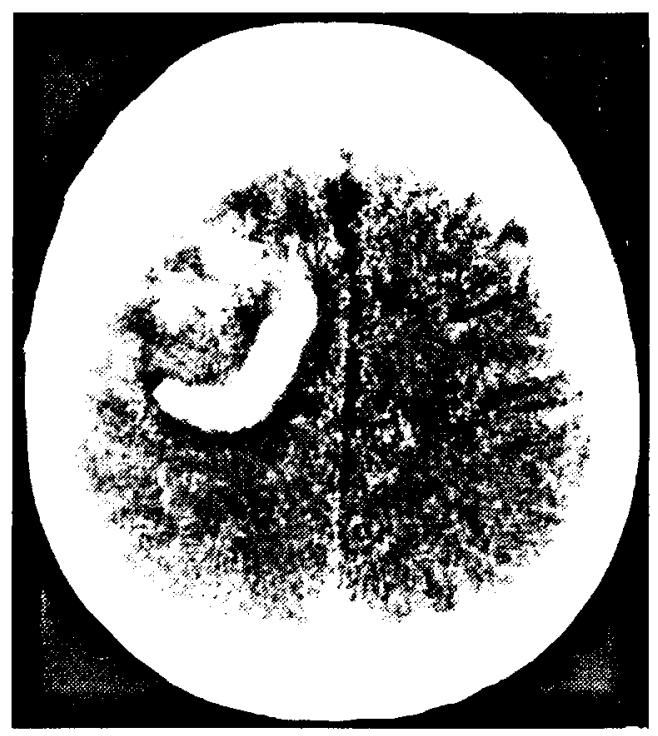

Fig. 5 Case 2. Computed tomography scan demonstrating a crescent high density area on the posteromedial surface of the partly calcified nidus.

\section{Discussion}

In cerebral AVMs, the annual risk of initial hemorrhage is approximately $2 \%$ to $3 \%{ }^{3)}$ A mortality is about $10 \%$ from the first hemorrhage, and increases to $20 \%$ from subsequent hemorrhages. ${ }^{15,22)}$ Prevention of hemorrhage is, therefore, obviously essential in management of AVMs. ${ }^{1-4)}$

Recent studies of angioarchitecture have provided information about hazardous structures in AVMs. ${ }^{9,10,23)}$ Aneurysmal vessel dilatations have been commonly stated as a risk factor of hemorrhage in these researches. Turjman et al. ${ }^{20)}$ reported that intranidal aneurysm and multiple aneurysms were correlated with hemorrhage by a use of superselective angiography. Perata et al. ${ }^{16)}$ emphasized that pedicle aneurysms, arising from the midportion of feeding artery pedicles, are at risk for recurrent rupture. In our series intranidal aneurysm and venous stenosis were two main structures related to hemorrhage. Interestingly, the intranidal aneurysm was regarded as a source of hemorrhage rather than the "pedicle" aneurysm in both illustrative cases, judging from location of the hematomas on MR images or CT scans. Intranidal aneurysm may not appear on angiograms taken after the hemorrhagic episode, as shown in Case 1 . Hence angiography should be repeated to analyze the latent angioarchitectures in patients with hemorrhage as an initial symptom.

Correlation between venous drainage and hemorrhage has been discussed by several authors. Viñuela et al., ${ }^{21)}$ Miyasaka et al., ${ }^{12)}$ and Nataf et al. ${ }^{13)}$ emphasized either stenosis or occlusion of venous drainage was a high risk factor of hemorrhage. There are, however, some controversies about this concept, and opposite results have been shown. ${ }^{8,20)}$ Such difference may be partly due to the selection bias of the patients. The previous studies based on the majority of patients with a clinical symptom of hemorrhage are apt to support a strong correlation between venous drainage and hemorrhage. Hemorrhage might have already modified venous drainage, and have led to venous stenosis or occlusion because of compression by the hematoma.

Studies concerning hemodynamics in AVMs have revealed that feeder arterial pressure is positively correlated to hemorrhage. ${ }^{6,18)}$ Norbash et al. ${ }^{14)}$ clearly demonstrated a significant decrease of feeding arterial pressure in patients with angiomatous change, which denotes transcortical arterial recruitment by AVM from adjoining vascular territories. No hemorrhagic events were associated with this kind of angioarchitecture during follow-up in our series, which supports the negative correlation between angiomatous change and hemorrhage. 
Surgical resection of the nidus can eliminate the risk of hemorrhage ${ }^{5)}$ Surgery is justified particularly in smaller AVMs, because mortality and morbidity are lower than natural risk. ${ }^{71}$ From our study, however, potentially hazardous lesions such as intranidal aneurysm and venous stenosis could be differentiated from stable structures, such as angiomatous change and arteriovenous fistula. Moreover, hemorrhage did often occur in large AVMs. When these dangerous lesions are delineated on angiographically the first treatment should be focused on them. In cases of large AVMs associated with such lesions, endovascular embolization would be a treatment of choice. Stereotactic radiosurgery is also likely to be effective in patients with intranidal aneurysm. ${ }^{17}$

\section{References}

1) Crawford PM, West CR, Chadwick DW, Shaw MDM: Arteriovenous malformations of the brain: Natural history in unoperated patients. I Neurol Neurosurg Psychiatry 49: 1-10, 1986

2) Fults D, Kelly DL: Natural history of arteriovenous malformations of the brain: A clinical study. Neurosurgery 15: 658-662, 1984

3) Graf CJ, Perret GE, Torner JC: Bleeding from cerebral arteriovenous malformations as part of their natural history. J Neurosurg 58: 331-337, 1983

4) Itoyama $Y$, Uemura S, Ushio Y, Kuratsu J, Nonaka N, Wada H, Sano Y, Fukumura A, Yoshida K, Yano T: Natural course of unoperated intracranial arteriovenous malformations: study of $\mathbf{5 0}$ cases. J Neurosurg 71: 805-809, 1989

5) Jomin M, Lesoin F, Lozes G: Prognosis for arteriovenous malformations of the brain in adults based on 150 cases. Surg Neurol 23: 362-366, 1985

6) Kader A, Young WL, Pile-Spellman J, Mast H, Sciacca RR, Mohr JP, Stein BM, The Columbia University AVM Study Project: The influence of hemodynamic and anatomic factors on hemorrhage from cerebral arteriovenous malformations. Neurosurgery 34: 801808,1994

7) Lussenhop AJ, Rosa L: Cerebral arteriovenous malformations. Indications for and results of surgery, and the role of intravascular techniques. J Neurosurg 60: 14-22, 1984

8) Marks MP, Lane B, Steinberg G, Chang P: Vascular characteristics of intracerevral arteriovenous malformations in patients with clinical steal. AJNR Am J Neuroradiol 12: 489-496, 1990

9) Marks MP, Lane B, Steinberg GK, Chang PI: Hemorrhage in intracerebral arteriovenous malformations: Angiographic determinants. Radiology 176: 807-813, 1990
10) Marks MP, Steinberg GK, Norbash A, Lane B: Vascular characteristics predictive of hemorrhage in cerebral AVM's. J Neurosurg 78: 346A, 1993

11) Miyasaka $Y$, Yada K, Kurata A, Tokiwa K, Irikura K, Tanaka R, Ohwada T, Kitahara T: Correlation between intravascular pressure and risk of hemorrhage due to arteriovenous malformations. Surg Neurol 39: 370-373, 1993

12) Miyasaka $Y$, Yada K, Ohwada T, Kitahara T, Kurata A, Irikura K: An analysis of the venous drainage system as a factor in hemorrhage from arteriovenous malformations. J Neurosurg 76: 239-243, 1992

13) Nataf F, Meder JF, Roux FX, Blustajn J, Merienne L, Merland JJ, Schlienger M, Chodkiewicz JP: Angioarchitecture associated with hemorrhage in cerebral arteriovenous malformations: a prognostic statistical model. Neuroradiology 39: 52-58, 1997

14) Norbash AM, Marks MP, Lane B: Correlation of pressure measurements with angiographic characteristics predisposing to hemorrhage and steal in cerebral arteriovenous malformations. AJNR Am J Neuroradiol 15: 809-813, 1994

15) Ondra SL, Troupp H, George ED, Schwar K: The natural history of symptomatic arteriovenous malformations of the brain: a 24-year follow-up assessment. J Neurosurg 73: 387-391, 1990

16) Perata HJ, Tomsick TA, Tew JM: Feeding artery pedicle aneurysms: association with parenchymal hemorrhage and arteriovenous malformation in the brain. $J$ Neurosurg 80: 631-634, 1994

17) Pollock BE, Flickinger JC, Lunsford LD, Bissonette DJ, Kondziolka D: Hemorrhage risk after stereotactic radiosurgery of cerebral arteriovenous malformations. Neurosurgery 38: 652-661, 1996

18) Spetzler RF, Hargraves RW, McCormick PW, Zabramski JM, Flom RA, Zimmerman RS: Relationship of perfusion pressure and size to risk of hemorrhage from arteriovenous malformations. J Neurosurg 76: 918-923, 1992

19) Spetzler RF, Martin NA: A proposed grading system for arteriovenous malformations. $J$ Neurosurg 65: 476-483, 1986

20) Turjman F, Massoud TF, Viñuela F, Sayre JW, Guglielmi G, Duckwiler G: Correlation of the angioarchitectural features of cerebral arteriovenous malformations with clinical presentation of hemorrhage. Neurosurgery 37: 856-862, 1995

21) Viñuela F, Nombela L, Roach MR, Fox AJ, Pelz DM: Stenotic and occlusive disease of the venous drainage system of deep brain AVM's. J Neurosurg 63: 180-184, 1985

22) Wilkins RH: Natural history of intracranial vascular malformations: a review. Neurosurgery 16: 421-430, 1985

23) Willinsky R, Lasjaunias $P$, Terbrugge $K$, Pruvost $P$; Brain arteriovenous malformations: Analysis of the angio-architecture in relationship to hemorrhage 
(based on 152 patients explored and/or treated at the hospital de Bicêtre between 1981 and 1986). J Neuroradiol 15: 225-237, 1988
Address reprint requests to: S. Hirai, M.D., Department of Neurosurgery, Chiba University School of Medicine, 1-8-1 Inohana, Chuo-ku, Chiba 260-8670, Japan. 